\title{
Coagulation Factor XII Congenital Deficiency in Women with Recurrent Miscarriage
}

\author{
Martin-Loeches Mariano ${ }^{1 *}$, Pallas Yadira ${ }^{1}$, Abad Ana ${ }^{2}$, Lloret Manuel ${ }^{1}$, Lopez-Galvez Jose Jesús ${ }^{1}$ \\ ${ }^{1}$ Department of Human Reproduction, “San Carlos” General Hospital, Denia (Alicante), Spain; ${ }^{2}$ Department of Haematology, “Ma- \\ rina Alta” University Hospital, Denia (Alicante), Spain. \\ Email: *mm-loeches@coma.es
}

Received May 13 ${ }^{\text {th }}, 2011$; revised July 23 ${ }^{\text {rd }}$, 2011; accepted August $5^{\text {th }}, 2011$.

\begin{abstract}
Factor XII (Hageman factor) is an important protease that plays a major role in the initiation of the intrinsic pathway of blood coagulation and fibrinolysis and kinin formation. It is still unclear whether factor XII deficiency causes any disorders during pregnancy. Because the main clinical feature in patients with factor XII deficiency is thrombosis rather than bleeding, low dose aspirin would be expected to prevent first trimester miscarriage and a decrease in factor XII level itself was found to be an independent risk factor in recurrent miscarriage. The woman in a 31-year-old patient, with personal and family antecedents without interest and preceding obstetrics of two spontaneous abortions in the first quarter of the pregnancy without apparent cause. In the study of infertility practiced emphasizes a partition of not more than one centimetre of length in the uterine found by hysteroscopy exploration and in the study of hipercoagulability a light deficiency of the factor XII. Himself guideline processing with low dose of aspirin (125 mgr/day) and preconception folic acid (5 mgr/day), remains expectant mother and in the week 12 of her third pregnancy itself guideline antitrombotic prophylaxis with heparin of low molecular weight by subcutaneous way. The pregnancy reaches the week 39 without incidents of interest and the expectant mother give birth of spontaneous form to health boy. Repeated abortions may be associated with reduced level of factor XII activity of unknown origin and low-dose aspirin may prevent miscarriage caused for decreased factor XII levels in patients with a history of recurrent first trimester miscarriage.
\end{abstract}

Keywords: Factor XII, Recurrent Miscarriage, Thrombofilia, Pregnancy Loss

\section{Introduction}

Factor XII (Hageman factor) is an important protease that plays a major role in the initiation of the intrinsic pathway of blood coagulation and fibrinolysis and kinin formation [1-4]. Although congenital factor XII deficiency (up to $50 \%$ of normal) is not associated with a clinical bleeding tendency, it can be identified on a routine coagulation test, such as a prolonged activated partial thromboplastin time [1,3,4]. This deficiency is a rare autosomal recessive disorder. It is still unclear whether factor XII deficiency causes any disorders during pregnancy. Disruption of this system may be a risk factor for early pregnancy losses and recurrent miscarriages and placental abruption were reported in cases with factor XII deficiency [2,5,6].

On the other hand, some cases of vascular thromboses have been reported in patients with factor XII deficiency [3].

It is well known that congenital thrombophilia is asso- ciated with fetal loss and to cause significant maternal complications, and possibly has an adverse effect on normal fetal development [7-9].

Thus, factor XII deficiency and hypofibrinolysis (mainly high plasminogen activator inhibitor activity) are the most frequent haemostasis-related abnormalities found in unexplained primary recurrent aborters. In patients with antiphospholipid antibodies or hypofibrinolysis, there is a non-inflammatory ongoing chronic elevation of markers of endothelial stimulation associated with coagulation activation. This should allow defining subgroups of patients for future therapeutic trials [7].

Both vascular and placental thromboses have been reported to be associated with recurrent fetal loss [1], factor XII deficiency may induce microthrombi in the uteri blood flow, which might prevent normal growth of the fetus [10-12].

Because the main clinical feature in patients with factor XII deficiency is thrombosis rather than bleeding, low dose aspirin would be expected to prevent first trimester 
miscarriage $[8,10,13]$.

Although there is a general consensus regarding the association between thrombophilia and midtrimester losses, the link with first-trimester miscarriages remains controversial [11] and a decrease in factor XII level itself was found to be an independent risk factor in recurrent miscarriage $[4,5,8,10,12,13]$ and data on the other factors either fail to show association or are quite limited [4].

The aim of this work was to say that factor XII deficiency is common in women with a history of recurrent miscarriage.

\section{Case Report}

31-year-old patient, with family antecedents of father, mother and two sisters that do not present hemorrhagic antecedents neither trombotics of interest; personal antecedents of menarquia to the 14 years old and normal menstruations; preceding obstetrics of two spontaneous abortions in the first quarter of the pregnancy without apparent cause.

Study is practiced of infertility with pelvic ultrasound, vaginal cytology and general and hormonal blood test, cariotipe in peripheral blood of both members of the normal couple, pelvic laparoscopy and hysteroscopy that report of uterus of normal external morphology and a partition of not more than one centimetre of length in the uterine fund.

The study of hipercoagulability practiced reports of time of protrombin of 13 seconds, Indicate of Quick of the $96 \%$, partial time of activated tromboplastin of 29 seconds and fibrinogen of $259 \mathrm{mgr} / \mathrm{dl}$; factor VIII of 116 $\mathrm{UI} / \mathrm{dl}$, factor vW: Rco of $102 \mathrm{UI} / \mathrm{dl}$, factor vW: Ag of 79 $\mathrm{UI} / \mathrm{dl}$, factor IX of $103 \mathrm{UI} / \mathrm{dl}$, factor XI of $70 \mathrm{UI} / \mathrm{dl}$ and factor XII of $48 \mathrm{UI} / \mathrm{dl}$; detection of specific inhibitors (PTT-THE, DVV-t and DPT) negative, anticardiolipin and antifosfolipid antibodies Ig $\mathrm{G}$ and Ig $\mathrm{M}$ negative, antigenic fibrinogen of $325 \mathrm{mgr} / \mathrm{dl}$, protein C of $114 \%$, protein S of $100 \%$, antitrombin III of $84 \%$ and active resistance Protein $\mathrm{C}$ active index of 3 (Table 1).

With the diagnosis of light deficiency of the factor XII, itself guideline processing with low dose of aspirin (125 $\mathrm{mgr} /$ day) and preconception folic acid (5 mgr/day). It remains expectant mother and in the week 12 of her third pregnancy study is practiced of hipercoagulability in which emphasizes an increase of the fibrinogen of 228 $\mathrm{mgr} / \mathrm{dl}$, factor XI of $79 \mathrm{UI} / \mathrm{dl}$ and factor XII of $62 \mathrm{UI} / \mathrm{dl}$ (levels of factor XII in the low limits of the normality) and himself guideline antitrombotic prophylaxis with heparin of low molecular weight by subcutaneous way (Table 2).

The expectant mother reaches the week 39 and gives spontaneous birth to a healthy male baby and weighting 3.800 grams and index of Apgar 9/10, without external
Table 1. Results of the basic coagulation and of the factors of the coagulation practiced the patient at the preconceptional moment and in the week 12 of pregnancy.

\begin{tabular}{ccc}
\hline Blood test & Preconcepcional & $\begin{array}{c}\mathbf{1 2}^{\mathrm{a}} \text { week of } \\
\text { pregnancy }\end{array}$ \\
\hline Basic Coagulation & & \\
APTT & $29 \mathrm{sec}$ & $37,3 \mathrm{sec}$ \\
Time of protrombin & $13 \mathrm{sec}$ & $12,7 \mathrm{sec}$ \\
Indicate of Quick & $96 \%$ & $92 \%$ \\
Fibrinogen & $259 \mathrm{mg} / \mathrm{dl}$ & $228 \mathrm{mg} / \mathrm{dl}$ \\
Coagulation Factors & & \\
VIII & $116 \%$ & \\
IX & $103 \%$ & $79 \%$ \\
XI & $70 \%$ & $62 \%$ \\
XII & $48 \%$ & \\
\hline
\end{tabular}

APTT = Activated partial time of tromboplastine; $\mathrm{sec}=$ seconds; $\mathrm{mg} / \mathrm{dl}=$ miligrams/deciliter.

Table 2. Results of the study of hipercoagulability and immunology practiced to the patient one preconcepcional and in the week 12 of pregnancy.

\begin{tabular}{ccc}
\hline Blood test & Preconcepcional & $\begin{array}{c}\mathbf{1 2}^{\text {a }} \text { week of } \\
\text { pregnancy }\end{array}$ \\
\hline Hipercoagulability & & \\
Protein C (activity) & $114.20 \%$ & $125 \%$ \\
Protein C resistence index & 2.78 & 3.1 \\
Protein S & $100 \%$ & $101.3 \%$ \\
Antitrombin III & $84 \%$ & $92 \%$ \\
Immunology & & \\
Anticardiolipin Ab Ig G & $11 \mathrm{IU} / \mathrm{ml}$ & $16.8 \mathrm{IU} / \mathrm{ml}$ \\
Anticardiolipin Ab Ig M & $<10 \mathrm{IU} / \mathrm{ml}$ & $12 \mathrm{IU} / \mathrm{ml}$ \\
Lupus anticoagulant & $1.12 \mathrm{IU} / \mathrm{ml}$ & $0.85 \mathrm{UI} / \mathrm{ml}$ \\
t-PA inhibitor & $3 \mathrm{IU} / \mathrm{ml}$ & $3.8 \mathrm{IU} / \mathrm{ml}$ \\
\hline
\end{tabular}

$\mathrm{Ab}=$ antibodies; Ig = Inmunoglobulin; IU/ml = Internacional Units/mililiter.

malformations neither internal apparent.

\section{Discussion}

Congenital factor XII deficiency is not associated with a clinical bleeding tendency, it can be identified on a routine coagulation test, such as a prolonged activated partial thromboplastin time [1,3,4]. It is still unclear whether factor XII deficiency causes any disorders during pregnancy. Recurrent miscarriages and placental abruption 
were reported in cases with factor XII deficiency $[2,5,6]$.

Recently, evidence has accumulated for the presence of the kallikrein-kinin system or plasma contact system in the fetoplacental unit. Kinins which are released within the placenta may play a role in regulating placental blood flow. This suggests that the plasma contact system may also have an important role in pregnancy [9] and the disruption of this system may be a risk factor for early pregnancy losses [6,12].

Congenital thrombophilia is known to cause significant maternal complications, and possibly has an adverse effect on normal fetal development such an increased risk of pregnancy-associated venous thrombosis and fetal loss $[7,9]$.

Thus, factor XII deficiency and hypofibrinolysis are the most frequent haemostasis-related abnormalities found in unexplained primary recurrent aborters [4,7].

Several studies have reported the presence of autoantibodies to the contact proteins in patients with recurrent early pregnancy losses. Disruption of this system may be a risk factor for early pregnancy losses [2,6,8-10] and antibodies to factor XII showed a strong and statistically significant association $[9,14]$.

In the another hand, Gris et al. [7] suggests that factor XII deficiency is not associated with recurrent miscarriage and that normal pregnancy and vaginal delivery are possible even in cases with congenital factor XII deficiency and assert that the possible correlation of factor XII deficiency with recurrent miscarriage merits revaluation.

Sotiriadis [4] and Inomo et al. [9] showed a strong association between recurrent pregnancy losses and decreased coagulation factor XII and Ogasawara et al. [11] and Pauer et al. [6], observed that the rate with abnormal factor XII is significantly higher than that with normal factor XII and say that a decrease in factor XII (but not in C protein, S protein or factor XIII) predicts subsequent miscarriage in patients with a history of first-trimester recurrent miscarriages and all of them agree with Jones et al. [10] and Ogasawara et al. [11] that low-dose aspirin is effective for treatment of recurrent miscarriage in patients with decreased coagulation factor XII [6,8,10,11].

Braulke et al. [1] and Pauer et al. [6] assert that repeated abortions may be associated with reduced level of factor XII activity of unknown origin and coincide with Gris et al. [7] and Daya [15] to define subgroups of patients for future therapeutic trials with this problem.

Fiedler and Wurfel [16] suggest that there is a varying degree of evidence for a benefit of heparin and aspirin in these syndromes. Heparin not only reduces the abortion rate but also lowers the risk for developmental retardation, premature birth and preeclampsia. The effects of heparin are not restricted to anticoagulation. It is directly or indi- rectly involved in the adhesion of the blastocyst to the endometrial epithelium and the subsequent invasion 3.

We do think that the possible association of factor XII deficiency with early spontaneous abortion deserves to be documented.

In conclusion, repeated abortions may be associated with reduced level of factor XII activity of unknown origin and low-dose aspirin may prevent miscarriage caused for decreased factor XII levels in patients with a history of recurrent first trimester miscarriage.

\section{REFERENCES}

[1] I. Braulke, M. Pruggmayer, P. Melloh, et al., "Factor XII (Hageman) Deficiency in Women with Habitual Abortion: New Subpopulation of Recurrent Aborters?” Fertility and Sterility, Vol. 59, No. 1, 1993, pp. 98-101.

[2] T. Matsuura, T. Kobayashi, T. Asahina, et al., "Is Factor XII Deficiency Related to Recurrent Miscarriage?” Semin Thromb Hemost, Vol. 27, 2001, pp. 115-120. doi:10.1055/s-2001-14069

[3] J. F. Schved, J. Ch. Gris, J. S. Neveu, et al., "Factor XII Congenital Deficiency and Early Spontaneous Abortion," Fertility and Sterility, Vol. 52, No. 2, 1989, pp. 335-337.

[4] A. Sotiriadis, A. Makrigiannakis, T. Stefos, E. Paraskevaidis and S. N. Kalantaridou, "Fibrinolytic Defects and Recurrent Miscarriage: A Systematic Review and Meta-Analysis,” Obstetrics \& Gynecology, Vol. 109, No. 5, 2007, pp. 1146-1155. doi:10.1097/01.AOG.0000260873.94196.d6

[5] D. W. Jones, M. J. Gallimore, M. Winter and M. More, "Pathogenic Antibodies to Coagulation Factors. Part II: Fibrinogen, Prothrombin, Thrombin, Factor V, Factor XI, Factor XII, Factor XIII, Protein C and Von Willebrand Factor,” Journal of Thrombosis and Haemostasis, Vol. 4, No. 1, 2006, pp. 282-284. doi:10.1111/j.1538-7836.2005.01712.x

[6] H. U. Pauer, P. Burfeind, H. Kostering, G. Emons and B. Hinney, "Factor XII Deficiency Is Strongly Associated with Primary Recurrent Abortions," Fertility and Sterility, Vol. 80, No. 3, 2003, pp. 590-594. doi:10.1016/S0015-0282(03)00788-X

[7] J. C. Gris, S. Ripart-Neveu, C. Maugard, et al., "Respective Evaluation of the Prevalence of Haemostasis Abnormalities in Unexplained Primary Early Recurrent Miscarriages, The Nimes Obstetricians and Haematologists (NOHA) Study," Thrombosis and Haemostasis, Vol. 77, No. 6, 1997, pp. 1096-1103.

[8] M. S. Ogasawara, K. Aoki, K. Katano, et al., "Factor XII but Not Protein C, Protein S, Antithrombin III, or Factor XIII Is a Predictor of Recurrent Miscarriage,” Fertility and Sterility, Vol. 75, No. 5, 2001, pp. 916-919. doi:10.1016/S0015-0282(01)01688-0

[9] A. Inomo, T. Sugi, Y. Fujita, et al., "The Antigenic Binding Sites of Autoantibodies to Factor XII in Patients with Recurrent Pregnancy Losses," Thrombosis and Haemostasis, Vol. 99, No. 2, 2008, pp. 316-323. 
[10] D. W. Jones, M. J. Gallimore and M. Winter, "Recurrent Abortion-Antibodies to Factor XII or a Decrease in Factor XII Levels?” Fertility and Sterility, Vol. 76, No. 6, 2001, pp. 1288-1289. doi:10.1016/S0015-0282(01)02917-X

[11] M. S. Ogasawara, Y. Iinuma, K. Aoki, et al., "Low-Dose Aspirin Is Effective for Treatment of Recurrent Miscarriage in Patients with Decreased Coagulation Factor XII,” Fertility and Sterility, Vol. 76, No. 1, 2001, pp. 203-204. doi:10.1016/S0015-0282(01)01819-2

[12] T. Sugi and T. Makino, "Antiphospholipid Antibodies and Kininogens in Pathologic Pregnancies: A Review," American Journal of Reproductive Immunology, Vol. 47, No. 5, 2002, pp. 283-288.

[13] D. W. Jones, I. J. MacKie, M. J. Gallimore and M. Winter, "Antibodies to Factor XII and Recurrent Fetal Loss in Pa- tients with the Anti-Phospholipid Syndrome," British Journal of Haematology, Vol. 113, No. 2, 2001, pp. 550552. doi:10.1046/j.1365-2141.2001.02776.x

[14] D. W. Jones, M. J. Gallimore and M. Winter, “Antibodies to Factor XII: A Possible Predictive Marker for Recurrent Foetal Loss,” Immunobiology, Vol. 207, No. 1, 2003, pp. 43-46.

[15] S. Daya, "Issues in the Etiology of Recurrent Spontaneous Abortion," Current Opinion in Obstetrics \& Gynecology, Vol. 6, No. 2, 1994, pp. 153-159. doi:10.1097/00001703-199404000-00008

[16] K. Fiedler and W. Wurfel, "Effectivity of Heparin in Assisted Reproduction,” European Journal of Medical Research, Vol. 9, No. 4, 2004, pp. 207-214. 